\title{
Junction Surface Recombination Concept as Applied to Silicon Solar Cell Maximum Power Point Determination Using Matlab/Simulink: Effect of Temperature
}

\author{
Bakary Dit Dembo Sylla1, Ibrahima Ly², Ousmane Sow ${ }^{3}$, \\ Babou Dione"1, Youssou Traore1, Grégoire Sissoko ${ }^{1}$ \\ ${ }^{1}$ Laboratory of Semiconductors and Solar Energy, Physics Department, Faculty of Science and Technology, University Cheikh \\ Anta Diop, Dakar, Senegal \\ ${ }^{2}$ Electromecanical department, Polytechnic School of Thiès, Thiès, Senegal \\ ${ }^{3}$ University Institute of Technology, University of Thiès, Thiès, Senegal \\ Email: gsissoko@yahoo.com
}

How to cite this paper: Sylla, B.D.D., Ly, I., Sow, O., Dione, B., Traore, Y. and Sissoko, G. (2018) Junction Surface Recombination Concept as Applied to Silicon Solar Cell Maximum Power Point Determination Using Matlab/Simulink: Effect of Temperature. Journal of Modern Physics, 9, 172-188. https://doi.org/10.4236/jmp.2018.92011

Received: December 15, 2017

Accepted: January 16, 2018

Published: January 19, 2018

Copyright $\odot 2018$ by authors and Scientific Research Publishing Inc. This work is licensed under the Creative Commons Attribution International License (CC BY 4.0).

http://creativecommons.org/licenses/by/4.0/

\begin{abstract}
In this work, we study the method for determining the maximum of the minority carrier recombination velocity at the junction $\mathrm{Sf}_{\max }$, corresponding to the maximum power delivered by the photovoltaic generator. For this, we study the temperature influence on the behavior of the front white biased solar cell in steady state. By solving the continuity equation of excess minority carrier in the base, we have established the expressions of the photocurrent density, the recombination velocity on the back side of the base Sb, and the photovoltage. The photocurrent density and the photovoltage are plotted as a function of Sf, called, minority carrier recombination velocity at the junction surface, for different temperature values. The illuminated I-V characteristic curves of the solar cell are then derived. To better characterize the solar cell, we study the electrical power delivered by the base of the solar cell to the external charge circuit as either junction surface recombination velocity or photovoltage dependent. From the output power versus junction surface recombination velocity $\mathrm{Sf}$, we have deduced an eigenvalue equation depending on junction recombination velocity. This equation allows to obtain the maximum junction recombination velocity $\mathrm{Sf}_{\max }$ corresponding to the maximum power delivered by the photovoltaic generator, throughout simulink model. Finally, we deduce the conversion efficiency of the solar cell.
\end{abstract}

\section{Keywords}

Silicon Solar Cell-Junction Surface Recombination Velocity-Maximum Power 


\section{Introduction}

Many techniques exist and provide photovoltaic generators to operate at maximum points of their characteristics [1] [2]. The method used in this work enables us to determine the maximum power point based on electronic transport parameters of the solar cell. Contrary to the most commonly used MPPT technical, which takes into account the controllers particularly adapted for managing a non-linear source by forcing the generator to work at its maximum power point (MPP) [3] [4] [5].

This study aims to determination of the maximum power point supplied by a photovoltaic generator in static regime under the effect of temperature. For this, we give through the continuity equation, the expressions of minority carrier generation rate, and the density of the excess minority carrier in the base [6] [7].

The expressions of the photocurrent density, the photovoltage, the recombination velocity of the minority carrier at the back surface $\mathrm{Sb}$ and the electrical power, all depending on temperature are produced and graphically represented as function of minority carrier recombination velocity at the junction [8] [9] [10].

The I(Sf)-V(Sf) characteristic curves of the photocurrent density as function of photovoltage, the power as a function of minority carrier recombination velocity at the junction or photovoltage dependent, have also graphically represented [11] [12] [13].

A transcendental equation giving the minority carrier recombination velocity to the maximum power points $\mathrm{Sf}_{\max }$ is determined. It is graphically represented by matlab/Simulink as a minority carrier recombination velocity at the junction Sf (Time (secs)). Finally, the graphical results are compared with those of the model [14] [15] [16].

\section{Theory}

Consider a crystalline silicon solar cell $\left(n^{+}-\mathrm{p}-\mathrm{p}^{+}\right)$. Its structure is illustrated in Figure 1.

$Z$ is the depth in the base of the solar cell measured from the junction emitterbase $(z=0)$ to the back surface $(z=H)$. $H$ is the base thickness.

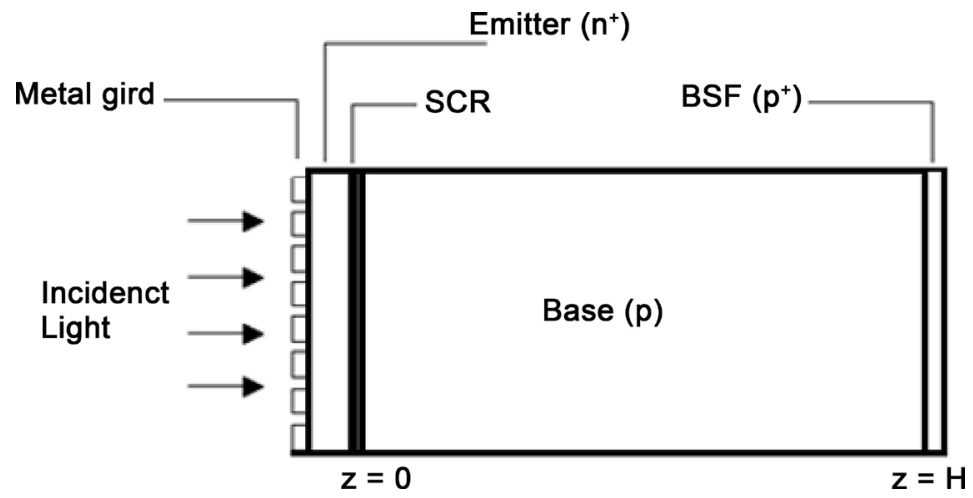

Figure 1. Structure of the silicon solar cell $\left(\mathrm{n}^{+}-\mathrm{p}-\mathrm{p}^{+}\right)$[17]. 
For a given illumination of the solar cell, different processes take place in the base, it is the absorption of the light, the minority carrier generation, bulk and surfaces recombination and diffusion. These processes can be simplified to the one dimensional continuity equation with boundary conditions:

$$
\frac{\partial^{2} \delta(z, T)}{\partial z^{2}}-\frac{\delta(z, T)}{L^{2}(T)}=-\frac{1}{D(T)} \cdot G(z)
$$

$\delta(z, T)$ represents the excess minority carrier density in the solar cell base at position $z$.

With

$$
L(T)=\sqrt{\tau \cdot D(T)}
$$

$L(T)$ is the minority carrier diffusion length in the base and is function of the temperature. It also represents the average distance traveled during the lifetime $(\tau)$ by the minority carrier before their recombination.

$D(T)$ is the electron diffusion coefficient in the base given by the well-known Einstein relation [18], temperature dependent, given as:

$$
D(T)=\mu(T) \frac{K_{b}}{q} T
$$

$\mu(T)$ is the mobility coefficient for electron and depends on the temperature [19], its expression is given by the following equation:

$$
\mu(T)=1.43 \times 10^{9} T^{-2.42} \mathrm{~cm}^{2} \cdot \mathrm{V}^{-1} \cdot \mathrm{s}^{-1}
$$

$K_{b}$ is the Boltzmann constant, $q$ is the elementary charge of an electron.

$G(z)$ is the minority carriers generation rate at position $\mathrm{z}$ in the base, given by [20] [21].

$$
G(z)=\sum_{i=1}^{3} a_{i} \mathrm{e}^{-b_{i} \cdot z}
$$

The coefficient $a_{i}$ and $b_{i}$ are obtained from tabulated values of the radiation in A.M 1.5 condition [22].

The excess minority carrier density is obtained from differential Equation (1) resolution and is given by.

$$
\delta(z, T)=A \cdot \cosh \left(\frac{z}{L(T)}\right)+B \cdot \sinh \left(\frac{z}{L(T)}\right)-\sum_{i=1}^{3} K_{i} \cdot \mathrm{e}^{-b_{i} \cdot z}
$$

The coefficients $A$ and $B$ are obtained with the boundary conditions at the emitter-base junction and at the back surface of the cell [22] [23]:

i) At the junction: emitter-base $(z=0)$

$$
\left.\frac{\partial \delta(z, T)}{\partial z}\right|_{z=0}=\left.\frac{S f}{D(T)} \delta(z=0, T)\right|_{z=0}
$$

ii) At the back side $(Z=H)$

$$
\left.\frac{\partial \delta(z, T)}{\partial z}\right|_{z=H}=-\left.\frac{S b}{D(T)} \delta(z=H, T)\right|_{z=H}
$$


$S f$ is the excess minority carrier recombination velocity at the junction emitter-base, it also characterizes the operating point of the solar cell [24] [25] on the illuminated current-voltage characteristic.

$S b$ is the excess minority carrier recombination velocity on the back of the base [25]. Its expression is obtained from the derivative (Figure 2) of the photocurrent density for large Sf values [17] [18] [19] [20].

$$
\left[\frac{\partial J p h}{\partial S f}\right]=0
$$

From the Equation (9), $S b$ is then expressed as dependent on the following parameters $L(T), D(T), \mu(T), b_{i}$ and $H$ :

$$
S b(T)=\frac{D(T)}{L(T)} \cdot \sum_{i=1}^{3} \frac{L(T) \cdot b_{i}\left(\mathrm{e}^{b_{i} \cdot H}-\cosh \left(\frac{H}{L(T)}\right)\right)-\sinh \left(\frac{H}{L(T)}\right)}{L(T) \cdot b_{i} \cdot \sinh \left(\frac{H}{L(T)}\right)+\cosh \left(\frac{H}{L(T)}\right)-\mathrm{e}^{b_{i} \cdot H}}
$$

\subsection{Photocurrent Density}

The expression of the photocurrent density is obtained from the density of the minority charge carriers in the base. It's given by the following relation:

$$
J p h(S f, T)=q \cdot D(T) \cdot\left[\frac{\partial \delta(z, S f, T)}{\partial z}\right]_{z=0}
$$

Figure 2 represents the photocurrent density profile as function of the junction

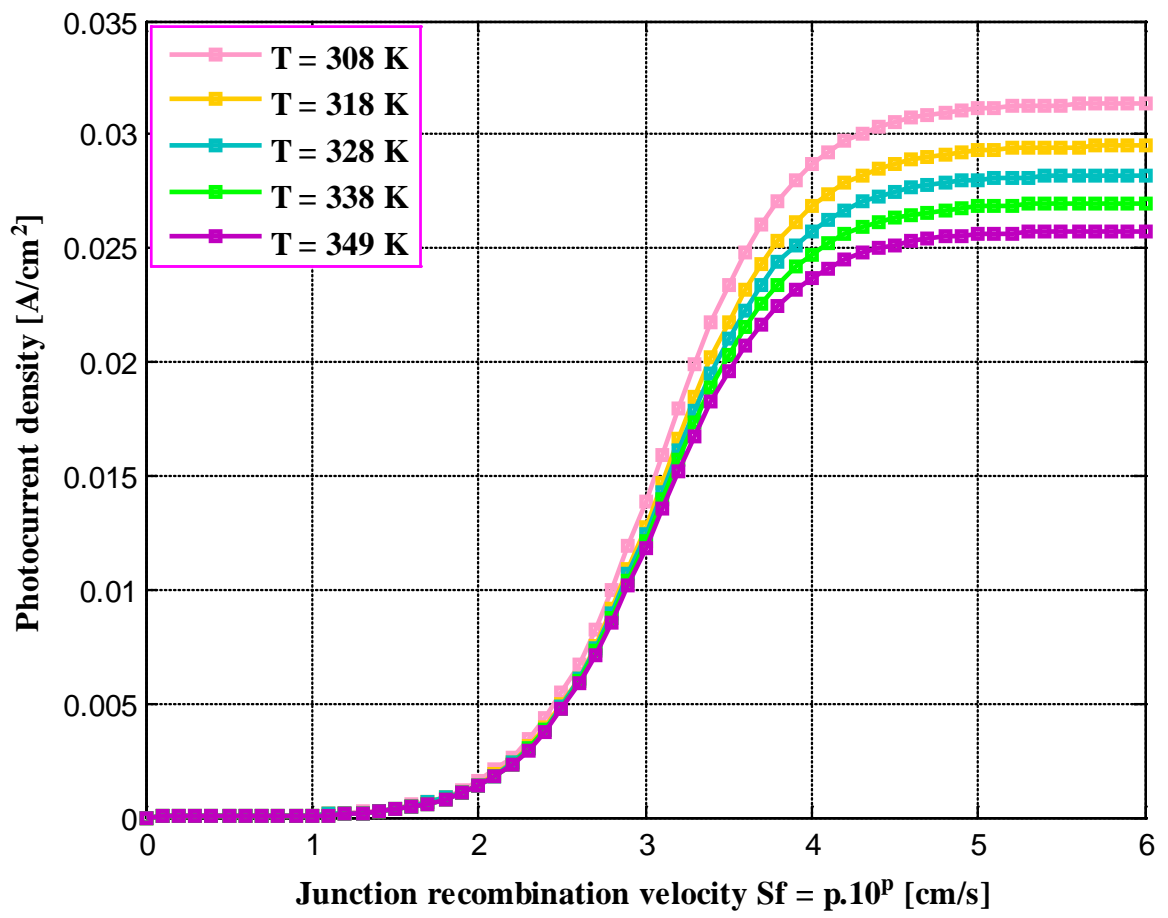

Figure 2. Photocurrent density versus junction recombination velocity for different temperature values. 
recombination velocity for different temperature values.

On this curve, the photocurrent density is very low in the vicinity of the open-circuit $\left(S f<2 \times 10^{2} \mathrm{~cm} / \mathrm{s}\right)$, then increases very rapidly with the junction minority carrier recombination velocity to reach an asymptotic value at large $S f$ values ( $S f>5 \times 10^{5} \mathrm{~cm} / \mathrm{s}$ ) corresponding to solar cell short-circuit photocurrent density. The short circuit current density decreases as the temperature increases. This decreasing due to the disordered movement of the charge carriers because the increasing of temperature causes a thermal agitation.

\subsection{Photovoltage}

The expression of the photovoltage at the terminal of the solar cell, when the latter is subjected to a multispectral illumination, is obtained by the Boltzmann relation [26].

$$
V p h(S f, T)=V_{T} \cdot \log \left[\frac{N_{b}}{n_{i}^{2}(T)} \delta(S f, T)+1\right]
$$

$V_{T}$ is the thermal voltage, it is given as follows:

$$
V_{T}=\frac{K_{b}}{q} T
$$

$T$ is the absolute temperature, it's included between $300-350 \mathrm{~K}$.

$N_{b}$ is the acceptor atom doping rate in the base.

$$
n_{i}^{2}(T)=A \cdot T^{3} \cdot \exp \left(-\frac{E_{g}}{K_{b} \cdot T}\right)
$$

$n_{i}(T)$ is the law of conservation (generation rate must be equal to recombination rates of charge carriers $n=p=n_{i}$ ) [27] [28].

$E_{g}$ is the energy gap, it corresponds to the difference between the energy of the conduction band Ec and the valence band $E_{g} E_{g}=1.12 \times 1.6 \times 10^{-19} \mathrm{~J}$,

$A$ is a specific constant of the material, $A=3.87 \times 10^{16} \mathrm{~cm}^{-3} \cdot \mathrm{K}^{-3 / 2}[18]$.

Figure 3 represents the photovoltage as function of junction recombination velocity for different temperature values.

Figure 3 shows that, at low junction minority carrier recombination velocity values, the photovoltage is maximal and constant, and corresponds to the open-circuit voltage (vicinity of the open-circuit). There is a blockage and storage of minority carriers at the junction. The phototvoltage decreases for large junction minority carrier recombination velocity values and it becomes low in the vicinity of the short-circuit (large $S f$ values), thus the minority carriers crossed over the junction and participate to the production of photocurrent. The increasing of temperature leads to a slight increase in the creation of electron hole pairs.

\subsection{Study of the $I(S f)-V(S f)$ Characteristic}

The profile of the $I(S f)-V(S f)$ characteristic for different temperature values is represented on Figure 4. 


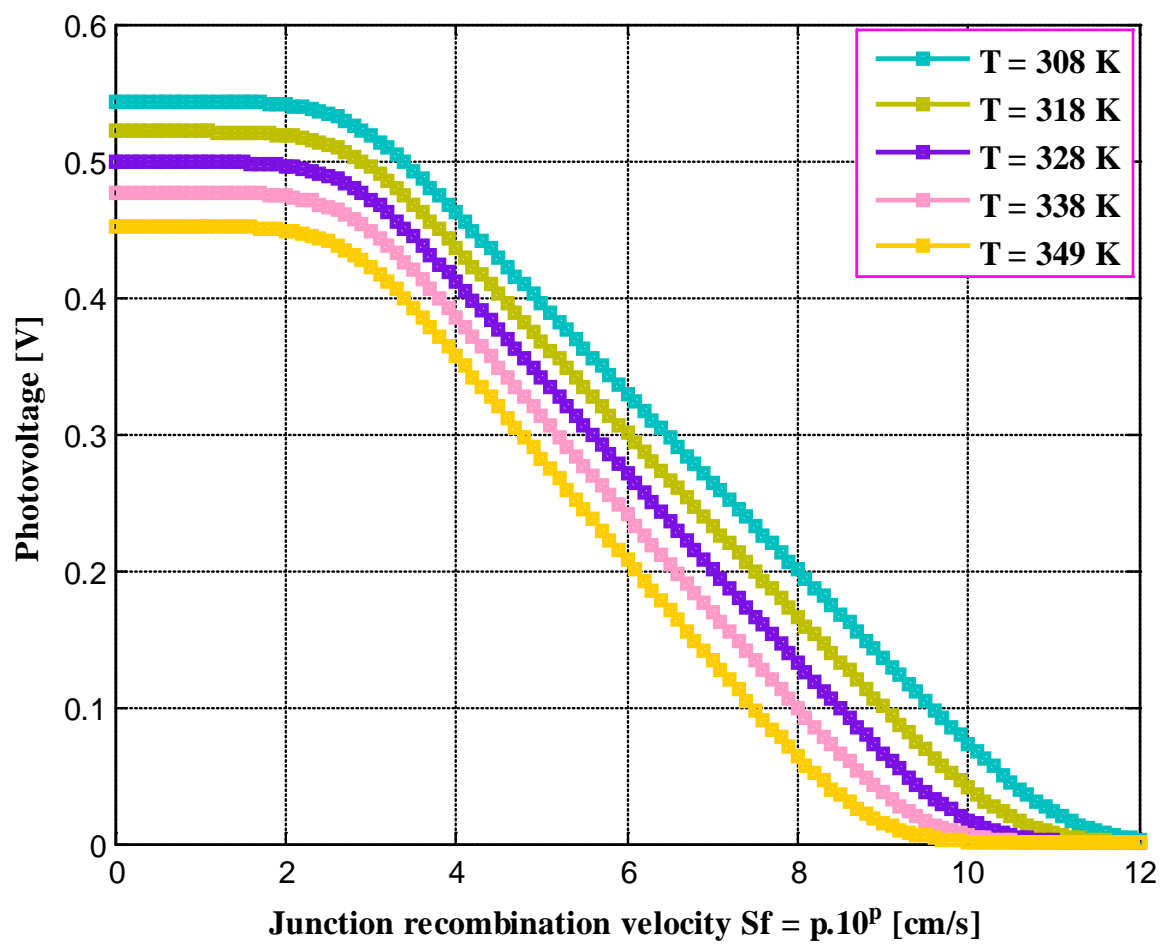

Figure 3. Photovoltage versus junction recombination velocity for different temperature values.

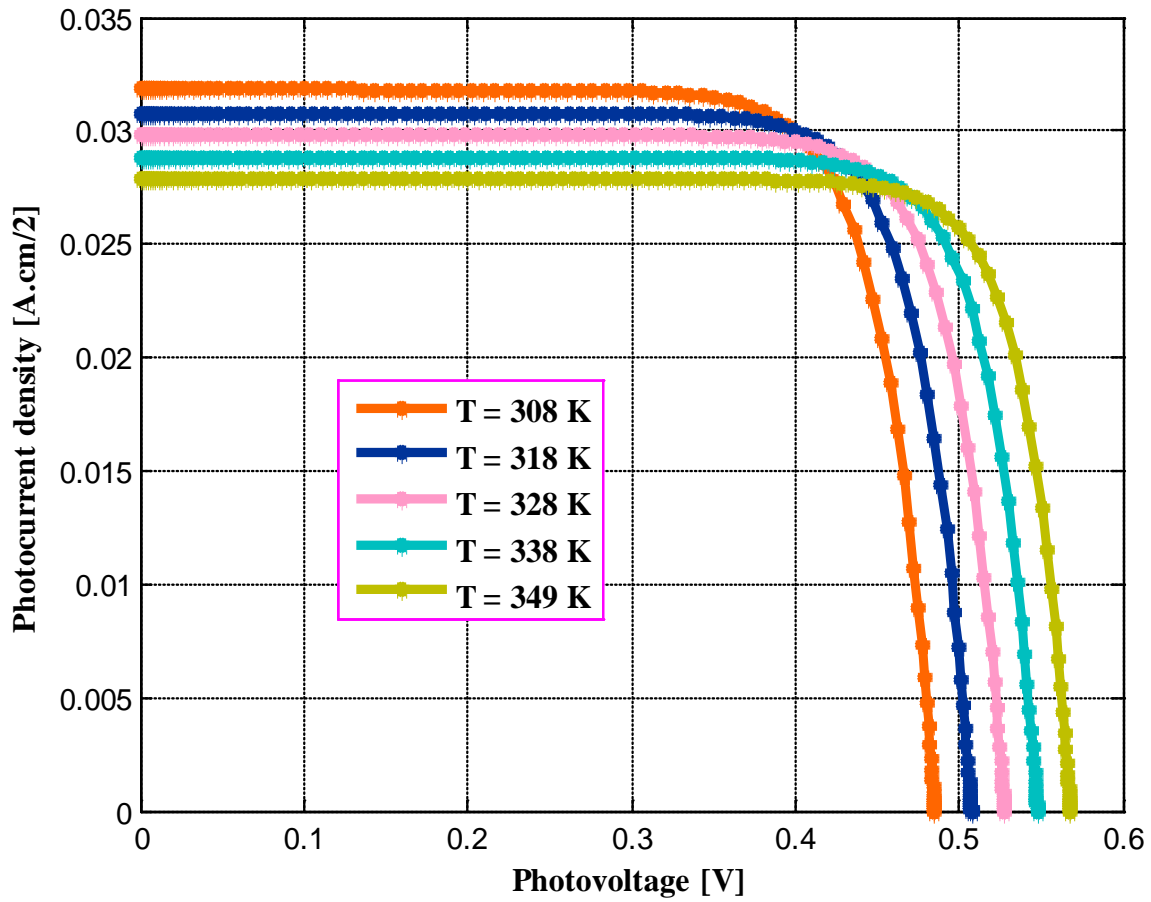

Figure 4. Photocurrent density versus photovoltage for different temperature values.

We notice that, the short-circuit photocurrent density decreases when the temperature increases and the open circuit voltage increases with increasing of temperature. 


\subsection{Study of the Power and the Maximum Power Point}

\subsubsection{Study of the Power}

The equivalent electrical circuit of an actual solar cell under illumination is represented by Figure 5. This circuit treats the solar cell as an ideal current generator which sells a photocurrent density depending on the illumination, connected in parallel with a diode and a shunt resistance $R_{s h}$ and in series with a series resistance Rs.

The Ohm law applied to Figure 5, allows to extract the solar cell base electrical power issued to the external charge circuit as following (15):

$$
P(S f, T)=V_{p h}(S f, T) \cdot I(S f, T)
$$

Applying the first law of Kirchhoff to the circuit of Figure 5, the current density supplied to the external charge circuit is given by the following relation [16].

$$
I(S f, T)=I_{p h}(S f, T)-I_{d}(S f, T)-I_{S h}(S f, T)
$$

$I_{d}$ is the diode current density, its expression is given by the following relation:

$$
I_{d}(S f, T)=q \cdot S f_{0} \cdot \frac{\left(n_{i}(T)\right)^{2}}{N_{b}} \cdot \exp \left(\frac{V_{p h}(S f, T)}{V_{T}}-1\right)
$$

$I_{s h}$ is the shunt current density, in the case of an ideal current generator, $\left(R_{\mathrm{sh}}\right.$ tends to infinity; $I_{S h}=0$ ).

$S f_{0}$ is the intrinsic junction recombination velocity associated with the losses of charge carriers induced by shunt resistance. It characterizes the good quality of the solar cell [29].

Figure 5 and Figure 6 represent the variations of the electrical power in function of the recombination velocity of the charge carriers at the junction and the photovoltage for different temperature values.

Figure 5 shows that, the power increases with the junction surface recombination velocity until a value $S f_{\max }$ then it decreases. The maximum power point varies with the temperature. Increasing photocurrent density is due to a decreasing of the energy larger band gap $E_{g}$. At the same time, we observe an increasing of the diode current density resulting a decreasing values of temperature.

\subsubsection{Maximum Power Point and Efficiency}

The maximum power point of a generator photovoltaic corresponds to the

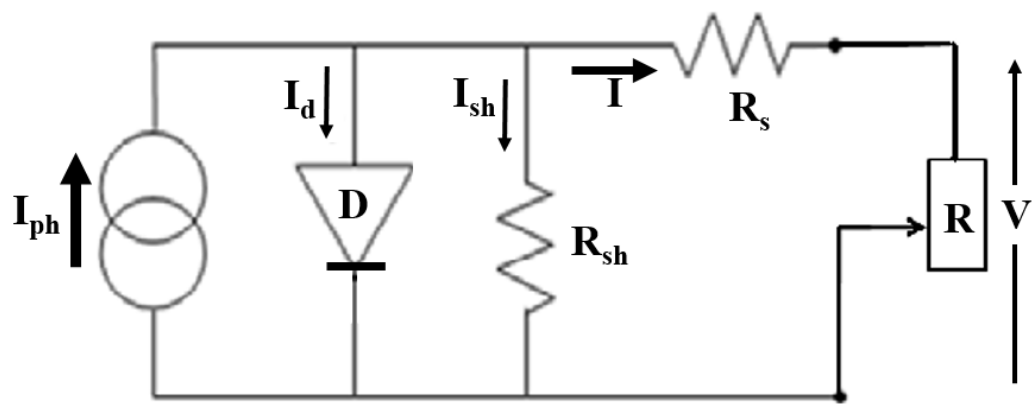

Figure 5. Equivalent electrical circuit of a solar cell [17]. 


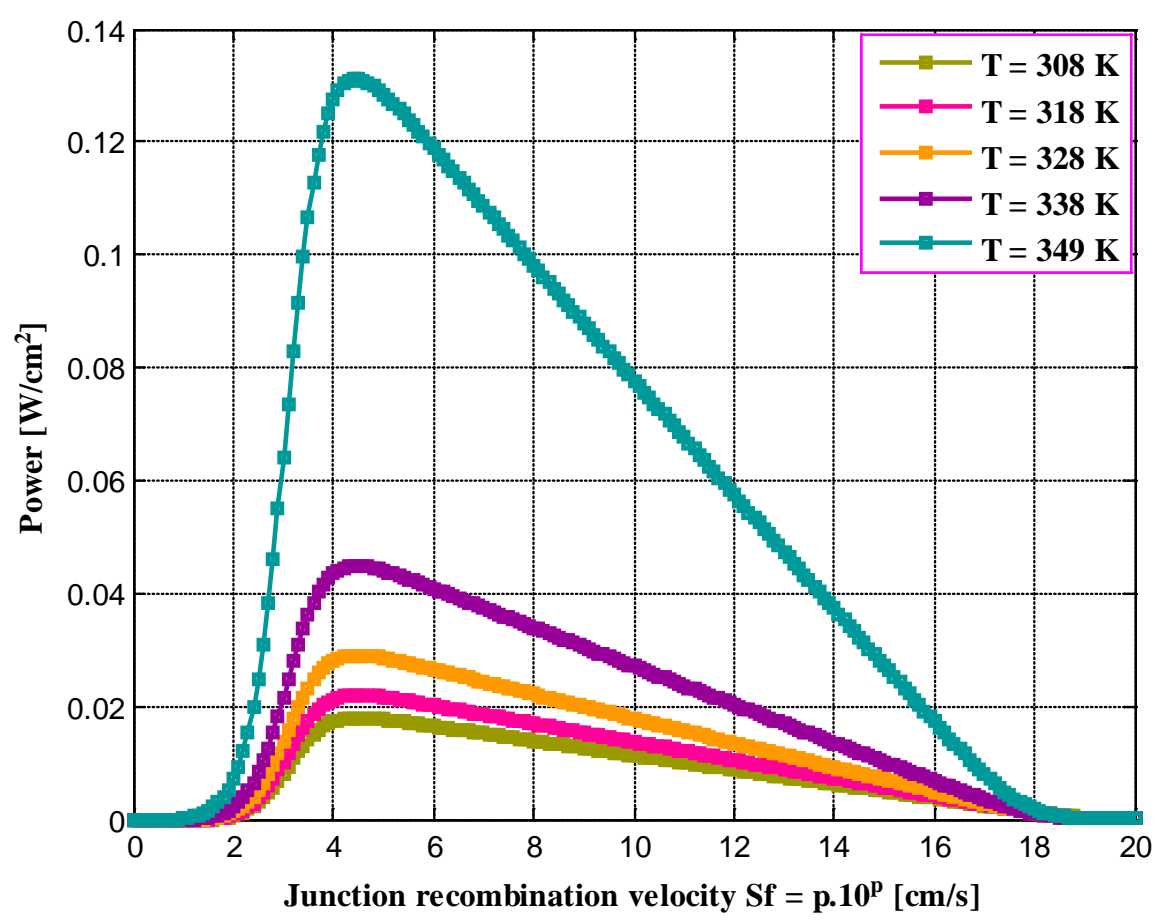

Figure 6. Solar cell power versus junction recombination velocity for different temperature values.

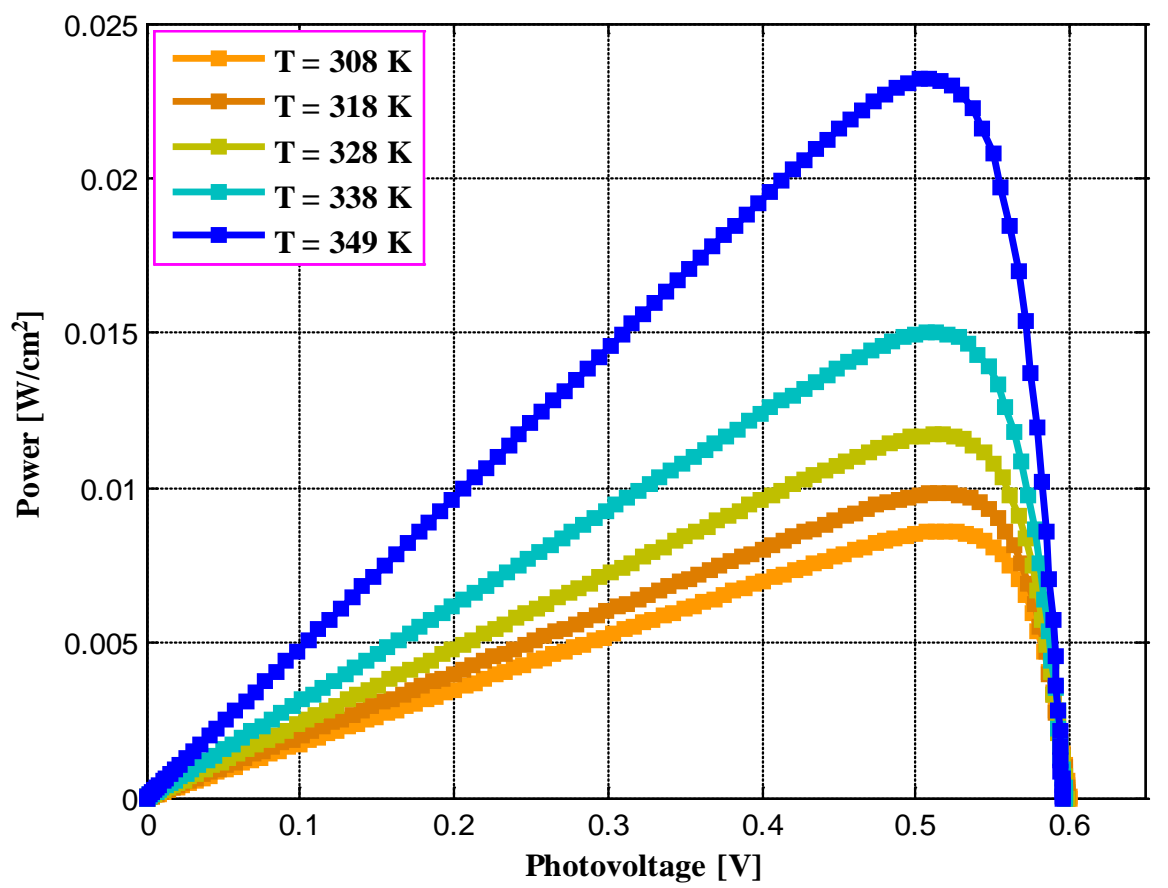

Figure 7. Solar cell power versus photovoltage for different temperature values.

photocurrent density-photovoltage couple generating the maximum electrical power of this solar cell.

Four essential data can be used to determine the photocurrent density-photovoltage characteristic of the photovoltaic generator [17]. 
- The photocurrent density of short-circuit noted $J_{s c}$

- The open-circuit voltage noted $V_{o c}$

- The maximal photocurrent density noted $J_{p h \max }$

- The maximal photovoltage noted $V_{p h \max }$

The product of the maximal photocurrent density and the maximal photovoltage $J_{p h \text { max }} \times V_{p h \text { max }}$ gives a maximal power $P_{\text {max }}$.

We determine the maximal minority carrier recombination velocity at the junction corresponding to the maximal power point [30] [31]. Let:

$$
\frac{\partial P}{\partial S f}=0
$$

Let $S f_{\max }$ denote this maximal junction recombination velocity corresponding to the maximal power point. It depends on:

i) electronic transport parameters $\left(L, \mu, D, S f, S b, \tau, n_{p}, N_{b}\right)$ in the solar cell that are related to physical phenomena,

ii) geometrical one $(H)$, i.e. in the $1 \mathrm{D}$ model

iii) material absorption coefficients $\left(b_{i}\right)$.

All these parameters are taking into account for the determination of the maximum power based on electron diffusion coefficient variation with temperature and the solar cell thickness $H$ [18].

From the Equation (18), the calculation gives the transcendental equation dependent of the junction minority carrier recombination velocity. and the temperature. It's given by the following expressions:

With

$$
M(S f, T)=\frac{1}{S f_{\max } L}\left[1-\frac{S f_{\max } L}{Y_{1} D+S f_{\max } L}\right]
$$

And

$$
\begin{aligned}
& N(S f, T) \\
& =\left[\frac{\Gamma_{\text {max }}(0, T)}{\left(\Gamma_{\text {max }}(0, T)+\frac{n_{i}^{2}}{N_{b}}\right) \cdot\left(S f_{\text {max }} \cdot L+Y_{1} \cdot D\right)}\right] *\left[\frac{1}{\log \left(\frac{N_{b} \cdot \Gamma_{\text {max }}(0, T)}{n_{i}^{2}}+1\right)}\right]
\end{aligned}
$$

$\Gamma_{\max }(0, T)$ is the density of the minority carrier on maximum power point, its expression is given by the following relation:

$$
\Gamma_{\max }(0, T)=K \cdot D \cdot\left[\frac{Y_{2}+Y_{1}-b_{i} \cdot L}{S f_{\max } \cdot L+Y_{1} \cdot D}\right]
$$

With

$$
\begin{gathered}
K=\frac{n \cdot a_{i} \cdot L^{2} \cdot \cos (\theta)}{D \cdot\left(L^{2} \cdot b_{i}^{2}-1\right)} \\
Y_{1}=\frac{D / L \cdot \sinh (H / L)+S b \cdot \cosh (H / L)}{D / L \cdot \cosh (H / L)+S b \cdot \sinh (H / L)}
\end{gathered}
$$




$$
Y_{2}=\frac{\left(D \cdot b_{i}-S b\right) \cdot \exp \left(-b_{i} \cdot H\right)}{D / L \cdot \cosh (H / L)+S b \cdot \sinh (H / L)}
$$

For the transcendental equation modelling a simulink model is used [32] [33]. This model is composed of an inputs block that includes a system allowing to define the set simulation type, simulation parameters, and preferences (powergui), the ramp block, which output a ramp signal starting at the specified time with the start time and initial output estimated at zero. To file block, allows the variable may be created as a matlab time series, an array, or a matlab structure. We used matlab time series which is used for any data type. It also allows defining the decimation and the sample time ( -1 for inherited). The constant block containing the different values of temperature. The $S f_{\max }$ block containing the expression of the transcendental equation. Finally, the output block composed of a creator bus, this block creates a bus signal from its inputs, it also allows defining the inherit bus signal names from input ports, the number of inputs, the signal in the bus and the output data type. The time scope block, this block defined the number of input ports (two in this model), input processing: elements as channels (sample based), time span of $S f_{\max }$ block (10 seconds), the time units in metric (based on time span), the time displays ofset at zero, show time axis-labels, the minimum and maximum limit of $y$-axis and $y$-axis label.

The model of the transcendental equation is represented in Figure 8 as follows:

The graphical resolution of this model provides the values of $S f_{\max }$ defined by the intercept point of two curves represented on Figure 9. To each operating point generating the maximum electrical power delivered by the photovoltaic generator corresponds to a $S f_{\max }$ value.

Figure 9 shows the increasing of the $S f_{\max }$ values then the temperature increases. Reflecting the increasing of the maximal power as the temperature increases.

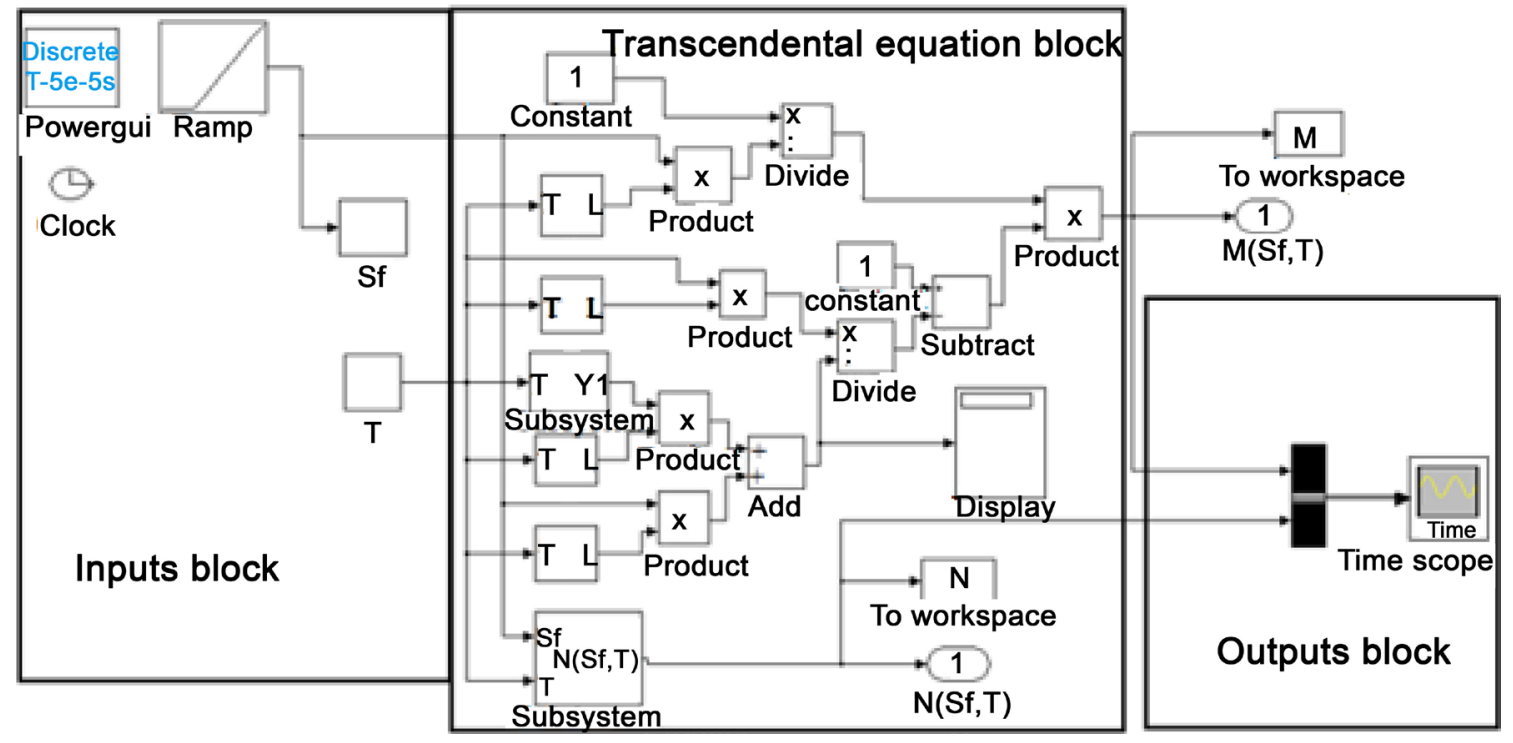

Figure 8. Simulink model of eigenvalue equation. 


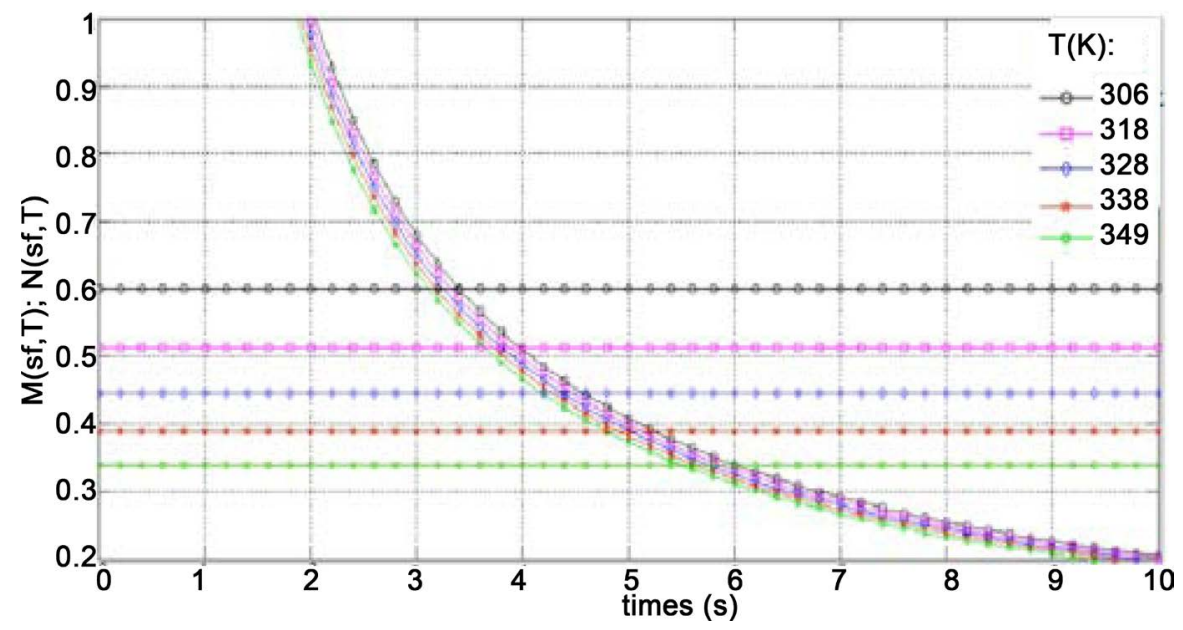

Figure 9. Graphical representation of simulink model of transcendental equation versus junction surface recombination velocity for different temperature values.

Table 1. The numerical values of $S f_{\max }$ corresponding to the maximal power point for different temperature values.

\begin{tabular}{ccc}
\hline Temperature $(\mathrm{K})$ & Points of intersection for each given temperature values $p(\mathrm{~cm} / \mathrm{s})$ & $\mathcal{S} f_{\max }(\mathrm{cm} / \mathrm{s})$ \\
\hline $308 \mathrm{~K}$ & 3.396 & $2.443 \times 10^{3}$ \\
$318 \mathrm{~K}$ & 3.883 & $7.620 \times 10^{3}$ \\
$328 \mathrm{~K}$ & 4.370 & $23.659 \times 10^{3}$ \\
$338 \mathrm{~K}$ & 4.913 & $80.909 \times 10^{3}$ \\
$349 \mathrm{~K}$ & 5.501 & $31.686 \times 10^{4}$ \\
\hline
\end{tabular}

We observe the intercept points on the figure corresponding to the $S f_{\max }$ values. These $S f_{\max }$ values correspond to an operating condition of the solar cell at the maximum power point.

The results obtained by the model on Figure 9 corresponding the numerical values of $S f_{\max }$ for each maximal power point are given in Table 1.

The influence of $S f_{\max }$ on the temperature can be plotted from a theoretical model of $S f_{\max }$ given by the following expression (25):

$$
S f_{\max }=b \cdot \mathrm{e}^{a T}
$$

The resolving of the right equation from Figure 10 provides the coefficients a and $b$ values follows as: $a=0.052 \mathrm{~cm} \cdot \mathrm{s}^{-1} / \mathrm{K}$, this value represents the slope corresponding to the vertical variation versus the horizontal variation of the right and $b=3.216 \mathrm{~cm} / \mathrm{s}$ corresponding a temperature of $305 \mathrm{~K}$, it is determined from the $\mathrm{y}$ intercepts and it is homogeneous to a maximal surface recombination velocity $S f_{\max } . S f_{\max }$ increases with temperature on a low positive slope.

\subsubsection{The Efficiency}

The conversion efficiency of the solar cell is a ratio between the maximal power supplied by the solar cell and the absorbed incident light power, writing as follows: 


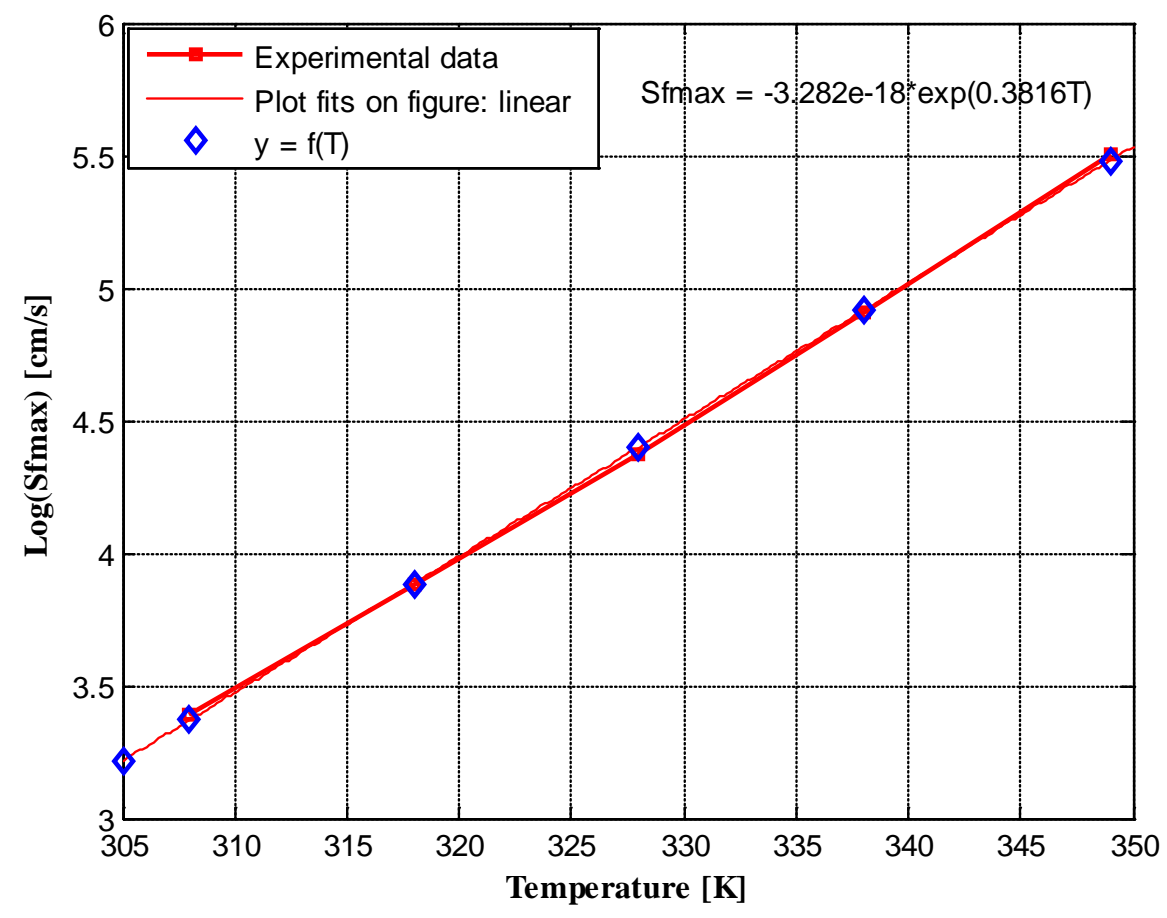

Figure 10. $\mathrm{Sf}_{\max }$ representation versus temperature.

Table 2. The photocurrent density $I_{\max }$ values, the photovoltage $V_{\max }$, the power Pmax and the efficiency $\Pi$ max corresponding to the maximal power point for different temperature values.

\begin{tabular}{|c|c|c|c|c|c|}
\hline Temperature (K) & $308 \mathrm{~K}$ & $318 \mathrm{~K}$ & $328 \mathrm{~K}$ & $338 \mathrm{~K}$ & $349 \mathrm{~K}$ \\
\hline$I_{\max }\left(\mathrm{mA} / \mathrm{cm}^{2}\right)$ & 0.03236 & 0.03132 & 0.03033 & 0.02935 & 0.02836 \\
\hline$I_{d}\left(S f_{\max }\right)(\mathrm{mA})$ & $3.023 \times 10^{-4}$ & $2.923 \times 10^{-4}$ & $2.83 \times 10^{-4}$ & $2.741 \times 10^{-4}$ & $2.65 \times 10^{-4}$ \\
\hline$V_{\max }(\mathrm{mV})$ & 0.4891 & 0.5113 & 0.5314 & 0.5514 & 0.5713 \\
\hline$P_{\max }\left(\mathrm{W} / \mathrm{cm}^{2}\right)$ & 0.015679 & 0.015864 & 0.015967 & 0.016032 & 0.016051 \\
\hline$\eta_{\max }(\%)$ & 15.679 & 15.864 & 15.967 & 16.032 & 16.051 \\
\hline
\end{tabular}

$P_{\text {incident }}$ is the absorbed incident light power by the solar cell, with $P_{\text {incident }}=100$ $\mathrm{mW} / \mathrm{cm}^{2}$ in the standards AM 1.5 condition [22].

For representation of efficiency, we have deduced on the characteristic curve of the photocurrent density as function of photovoltage according to Figure 4, the graphical values corresponding to the maximal power point, the maximal photocurrent density, the maximal photovoltage, the maximal power and the maximal conversion efficiency of the solar cell for different temperature values. These results are given in Table 2 .

Figures 11-13 represent the maximal photocurrent density $I_{\max }$, the maximal photovoltage $V_{\max }$ and the maximal conversion efficiency $\eta_{\max }$ of the solar cell as function of temperature. 


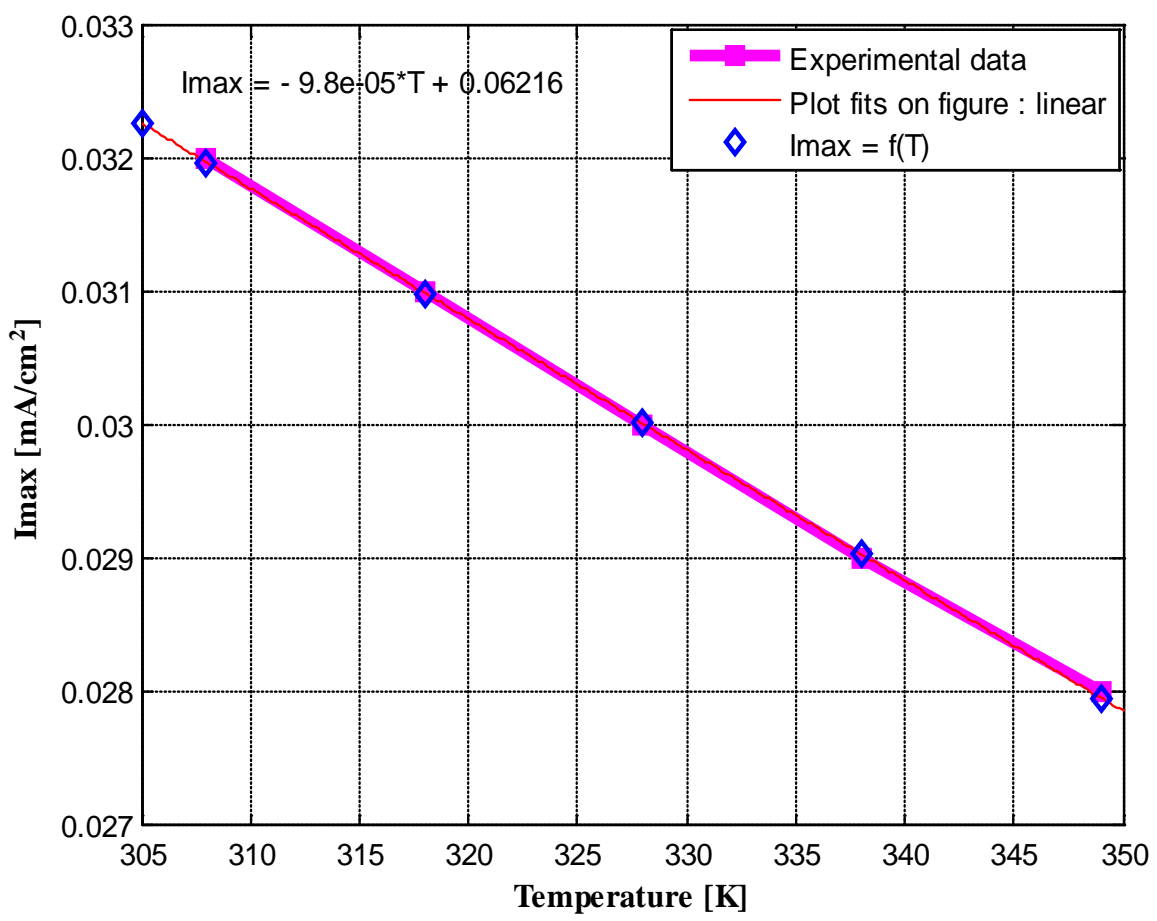

Figure 11. The maximal photocurrent versus temperature.

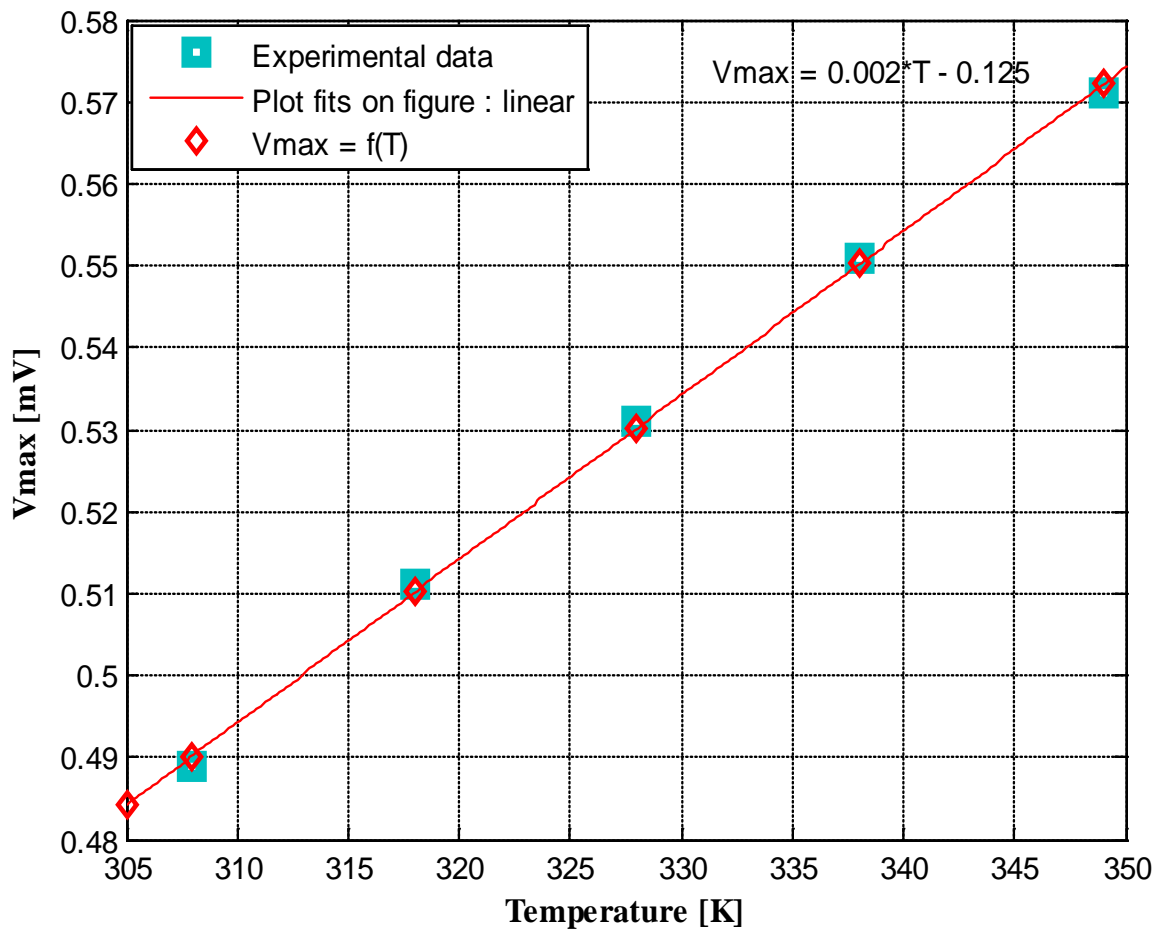

Figure 12. The maximal photovoltage versus temperature.

The resolution of line equation $y=\gamma T+\chi$, allows to obtain the line coefficient $\gamma$ and $\chi$ from Figure 11, with $\gamma=-9.756 \times 10^{-5} \mathrm{~mA} \cdot \mathrm{cm}^{-2} / \mathrm{K}$ and $\chi=0.03227$ $\mathrm{mA} / \mathrm{cm}^{-2}$ corresponding at the temperature of $305 \mathrm{~K}$. On this curve, we notice a decreasing of the maximal photocurrent $I_{\max }$ when the temperature increases, 


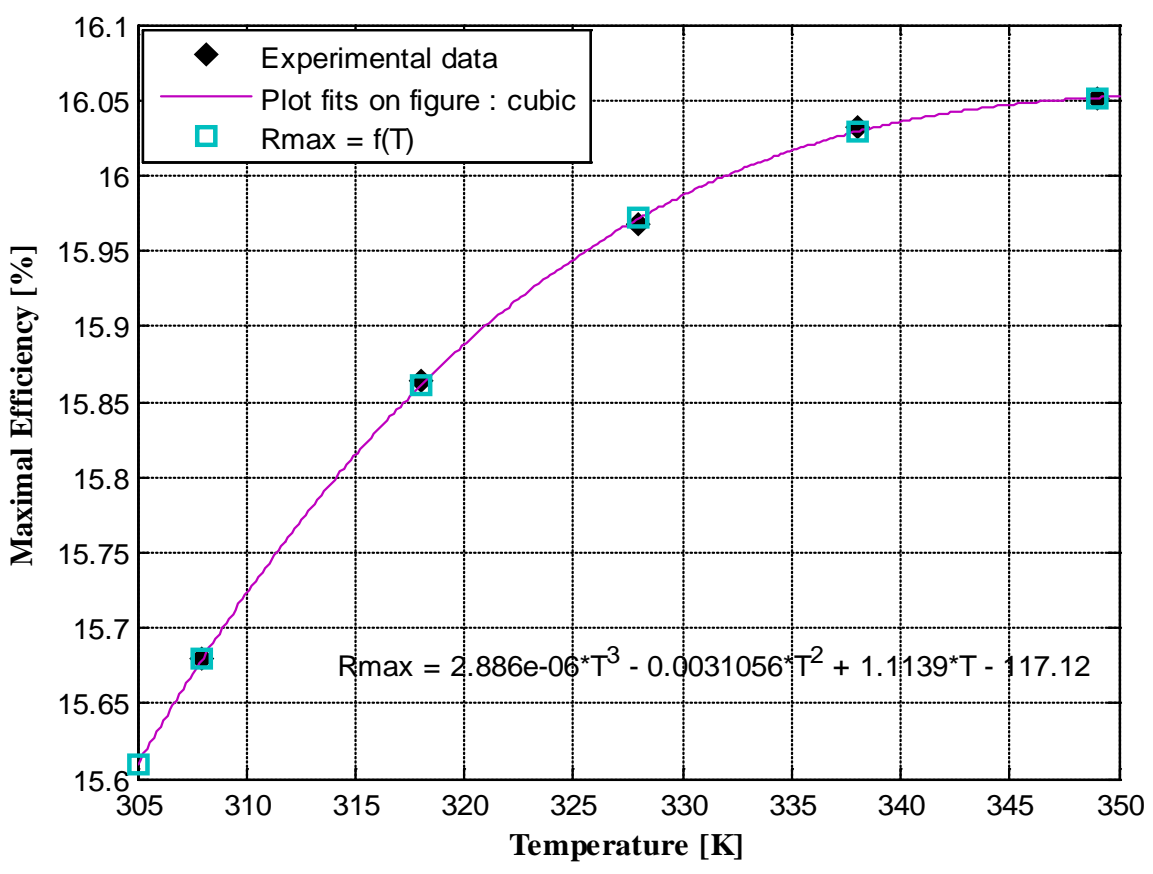

Figure 13. The maximal conversion efficiency versus temperature.

that explains a negative slope of the line. Therefore the decreasing of the photocurrent density as the temperature increases is realized.

The graphical representation of the maximal photovoltage versus temperature is given by Figure 12 .

In Figure 12, the resolution of line equation provide the coefficient values $\gamma=$ $0.002 \mathrm{mV} / \mathrm{K}$ and $\chi=0.4842 \mathrm{mV}$ for a temperature of $305 \mathrm{~K}$. We notice a low positive slope, it means that the photovoltage is maximal and is equal to the open-circuit voltage. The increasing of the temperature implies a minor increasing of the creation electron-hole pairs.

Figure 13 represents the variation of the maximal photovoltaic efficiency conversion as function of temperature.

These results shows that, the maximal junction recombination velocity $S f_{\max }$, the maximal photovoltage and the conversion efficiency photovoltaic increase when the temperature increases, contrary the maximal photocurrent density which decreases with increasing of temperature. This shows the variation of the maximum power point as the temperature increases [34] [35]. The method in this work shows us, how to optimize the electrical power supplied by the solar cell, by use of $S f_{\max }$ as a research function of the maximal power point. The method is mostly based on the variation of electron diffusion coefficient in the base $\mathrm{D}$, the diffusion length $\mathrm{L}$, the mobility coefficient of the electron $\mu$, the intrinsic concentration of minority carriers in the base (ni) and the recombination velocity of the charge carriers at the back side $\mathrm{Sb}$ all in function of temperature with the possibility to vary the thickness of the base, the electron lifetime in the base and the electron doping rate $\mathrm{Nb}$. Its strength is that, its depend on the electronic structuration parameters based on the physical mechanism of solar cell, contrary 
the converters and different tracking systems forcing the solar cell operating at the maximum power point (MPP) based on the macroscopic parameter of solar cell [36] [37].

\section{Conclusions}

In this work, after resolution the expression of the density of the minority charge carriers in excess in the base, the photocurrent density and the photovoltage, the $\mathrm{I}-\mathrm{V}$ characteristic is proposed. This study shows us a decreasing of the shortcircuit photocurrent and an increasing of the open-circuit photovoltage when the temperature increases. The decreasing of the short-circuit photocurrent manifests by a decreasing of the density of the excess minority carrier which crosses the junction when the temperature increases, which leads a increasing of the open-circuit photovoltage.

From the i-v characteristic of Figure 4, we studied the delivered electrical power by the base of the solar cell as the function of the density of minority charge carriers at the junction Sf and the photovoltage (Figure 6 and Figure 7). We note that the power increases with the recombination velocity of the charge carriers at the junction Sf and of the photovoltage until a maximal value which represents the maximum power then it decreases and cancel of a values corresponding of the open-circuit photovoltage (large Sf).

A transcendental equation allowing to obtain the maximal recombination velocity of the charge carriers $\mathrm{Sf}_{\max }$ corresponding to the maximal power point of the solar cell is determined as the function of temperature. It depends only on phenomelogical and geometrical parameters of the solar cell $(\mathrm{L}, \mu, \mathrm{D}, \mathrm{Sf}, \mathrm{Sb}, \tau$, $\mathrm{ni}, \mathrm{Nb}$ and $\mathrm{H}$ ) and the material absorptions coefficients bi, in the determination of the maximum power based on variation of the electron diffusion coefficient in the base as a function of temperature and the thickness $\mathrm{H}$ of the solar cell [18].

The transcendental equation is modeled from a simulink model (Figure 8), then graphically represented in Figure 9, and allows to extract the numerical values of $\mathrm{Sf}_{\max }$ for different values of the temperature noted in Table 1. The results in Table 1 show that the recombination velocity of the charge carriers at the junction corresponding to the maximal power point increases, and varies with the temperature (Figure 9). Finally, we studied the conversion efficiency of the solar cell from the graphical values extracted of the I- $\mathrm{V}$ characteristic curve of Figure 4, then plotted $I_{\max }, V_{\max }$ and $\eta_{\max }$ (Figures 11-13) as the function of the temperature compared to the $\mathrm{Sf}_{\max }$ values of Figure 10 obtained from the simulink model (Figure 8 and Figure 9).

\section{References}

[1] Benmoussa, W.C., Amara, S. and Zerga, A. (2007) Optimisation du rendement d'une photopile. Revue des Energies Renouvelables ICRESD-07 Tlemcen, 301-306.

[2] Gueye, S., Diallo, H.L., Ndaye, M., Dione, M.M. and Sissoko, G. (2013) International Journal of Emerging Technology and Advanced Engineering (IJTEA), 3, 1-9.

[3] Barro, F.I., Mbodji, S., Ndiaye, M., Ba, E. and Sissoko, G. (2008) Influence of Grains 
Size and Grains Boundaries Recombination on the Space-Charge Layer Thickness z of Emitter-Base Junction's $\mathrm{n}^{+}-\mathrm{p}-\mathrm{p}^{+}$Solar Cell. Proceedings of 23 rd European Photovoltaic Solar Energy Conference and Exhibition, 604-607.

[4] Ndoye, S., Ndiaye, M., Diao, A., Dione, M.M., Diarisso, D., Bama, A.O.N., Ly, I., Sow, G., Maiga, A.S., Foulani, A., Barro, F.I. and Sissoko, G. (2010) Modelling and Simuling the Powering System of a Base Transmitter Station with a Standalone Photovoltaic Generator. Proceedings of 25th European Photovoltaic Solar Energy Conference and Exhibition, 5208-5211.

[5] Diarisso, D., Ly, I., Sow, G., Sow, O., Gaye, I., Barro, F.I. and Sissoko, G. (2002) Research Journal of Applied Sciences, Engineering and Technology, 4, 3740-3745.

[6] Barro, F.I., Maiga, A.S., Wereme, A. and Sissoko, G. (2010) Phys. Chem. News, 56, 76-84.

[7] Sissoko, G., Correa, A., Nanema, E., Diarra, M.N., Ndiaye, A.L. and Adj, M. (1998) Recombination Parameters Measurement in Silicon Double Sided Surface Field Cell. Proceeding of the World Renewable Energy Congress, 20-25 September 1998, 1856-1859.

[8] Gaye, I., Corréa, A., Ba, B., Ndiaye, A.L., Nanéma, E., Ba, A.B.B., Adj, M. and Sissoko, G. (1996) Renewable Energy, 3, 1598-1601.

[9] Ly, I., Wade, M., Diallo, H.L., EL Moujtaba, M.A.O., Lemtabott, O.H., Mbodji, S., Diasse, O., Ndiaye, A., Gaye, I., Barro, F.I., Wereme, A. and Sissoko, G. (2011) Irradiation Effect on the Electrical Parameters of a Bifacial Silicon Solar Cell under Multispectral Illumination. Proceedings of 26 th European Photovoltaic Solar Energy Conference and Exhibition, 785-788.

[10] Sow, O., Zerbo, I., Mbodji, S., Ngom, M.I., Diouf, M.S. and Sissoko, G. (2012) International Journal of Sciences and Technology, 1, 230-246.

[11] Corréa, A., Gaye, I., Ba, B., Ndiaye, A.L. and Sissoko, G. (1994) Renewable Energy, 5, 166-168.

[12] Madougou, S., Made, F., Boukary, M.S. and Sissoko, G. (2007) Advanced Materials Research, 18-19, 303-312.

[13] Mbodji, S., Ly, I., Diallo, H.L., Dione, M.M., Diasse, O. and Sissoko, G. (2012) Research Journal of Applied Sciences, Engineering and Technology, 4, 1-7.

[14] Zoungrana, M., Dieng, B., Lemrabott, O.H., Touré, F., Ould EL Moujtaba, M.A., Sow, M.L. and Sissoko, G. (2012) Research Journal of Applied Sciences, Engineering and Technology, 4, 2967-2972.

[15] Sissoko, G., Nanéma, E., Corréa,A., Biteye, P.M., Adj, M. and Ndiaye, A.L. (1996) Renewable Energy, 3, 1848-1851.

[16] Mbodji, S., Ly, I., Diallo, H.L., Dione, M.M., Diasseand, O. and Sissoko, G. (2012) Research Journal of Applied Sciences, Engineering and Technology, 4, 1-7.

[17] Nam, L., Rodot, M., Nijs, J., Ghannam, M. and Coppye, J. (1992) Journal de Physique III, EDP Sciences, 2, 1305-1316.

[18] Diouf, M., Gaye, S., Thiam, I., Fall, A., M, M.F., Ly, I. and Sissoko, G. (2014) Current Trends in Technology \& Sciences, 3, 372-375. http://www.ctts.in/

[19] Kunst, M. and Sanders, A. (1992) Semiconductor Science and Technology, 7, 51-59.

[20] Zerbo, I., Koalaga, Z., Barro, F.I., Zougmore, F., Ndiaye, A.L., Diao, A. and Sissoko, G. (2004) Journal des Sciences, 4, 42-46.

[21] Furlan, J. and Amon, S. (1985) Solid-State Electronics, 28, 1241-1243. https://doi.org/10.1016/0038-1101(85)90048-6 
[22] Mohammad, S.N. (1987) Journal of Applied Physics, 28, 767-772.

[23] Sissoko, G., Museruka, C., Corréa, A., Gaye, I. and Ndiaye, A.L. (1996) Renewable Energy, 3, 1487-1490.

[24] Sissoko, G., Sivoththanam, S., Rodot, M. and Mialhe, P. (1992) Constant Illumination-Induced Open Circuit Voltage Decay (CIOCVD) Method, as Applied to High Efficiency Si Solar Cells for Bulk and Back Surface Characterization. 11th European Photovoltaic Solar Energy Conference and Exhibition, Poster 1B, Montreux, 12-16 October 1992, 352-354.

[25] Diallo, H.L., Maiga, A.S., Wereme, A. and Sissoko, G. (2008) The European Physical Journal Applied Physics, 42, 203-211. https://doi.org/10.1051/epjap:2008085

[26] Thurmond, C.D. (1975) Journal of the Electrochemical Society, 122, 133-141. https://doi.org/10.1149/1.2134410

[27] El-Adawi, M.K. and Al-Nuaim, I.A. (2002) Vacum, 64, 33-36. https://doi.org/10.1016/S0042-207X(01)00370-0

[28] Peykov, P. and Aceves, M. (2004) Superficies y Vacío, 17, 29-31.

[29] Thiam, N.D., Diao, A., Ndiaye, M., Dieng, A., Thiam, A., Sarr, M., Maiga, A.S. and Sissoko, G. (2012) Research Journal of Applied Sciences, Engineering and Technology, 4, 4646-4655.

[30] Ly Diallo, H., Wade, M., Ly, I., NDiaye, M., Dieng, B., Lemrabott, O.H., Maïga, A.S. and Sissoko, G. (2002) Research Journal of Applied Sciences, Engineering and Technology, 4, 1672-1676.

[31] Ly Diallo, H., Dieng, B., Ly, I., Dione, M.M., Ndiaye, M., Lemrabott, O.H., Bako, Z.N., Wereme, A. and Sissoko, G. (2002) Research Journal of Applied Sciences, Engineering and Technology, 4, 2626-2631.

[32] Dione, B., Sow, O., Wade, M., Ibrahima, L.Y., Mbodji, S. and Sissoko, G. (2016) Experimental Processus for Acquisition Automatic Features of I-V Properties and Temperature of the Solar Panel by Changing the Operating Point. Scientific Research Publishing Inc., 3985-4000.

[33] Na, W., Carley, T., Ketcham, L., Zimmer, B. and Chen, P. (2016) Journal of Power and Energy Engineering, 4, 61-76. https://doi.org/10.4236/jpee.2016.49006

[34] Diouf, M.S., Ly, I., Wade, M., Diatta, I., Traore, Y., Ndiaye, M. and Sissoko, G. (2016) Journal of Scientific and Engineering Research, 3, 289-297.

[35] Sy, K.M., Diène, A., Tamba, S., Diouf, M.S., Diatta, I., Dièye, M., Traoré, Y. and Sissoko, G. (2016) Journal of Scientific and Engineering Research, 3, 433-445.

[36] Kechar, E., Azzag, E. and Touaibia, I. (2015) International Journal of Scientific Research \& Engineering Technology, 3, 71-77.

[37] Abbes, H., Abid, H., Loukil, K., Toumi, A. and Abid, M. (2013) International Journal of Control, Energy and Electrical Engineering, 17, 1-6. 